\title{
Pulmonary vein stenosis_novel strategies for a challenging and resistant condition?
}

\author{
Anna N. Seale, MB BChir, MD, ${ }^{a}$ and Piers E. F. Daubeney, DM, FRCPCH \\ From the a Department of Paediatric Cardiology, Birmingham Children's Hospital and University of Birmingham; \\ and ${ }^{\mathrm{b}}$ Department of Paediatric Cardiology, Royal Brompton Hospital and the National Heart and Lung institute, \\ Imperial College, London, United Kingdom. \\ Disclosers: Authors have nothing to disclose with regard to commercial support. \\ Received for publication Nov 20, 2015; accepted for publication Nov 20, 2015. \\ Address for reprints: Anna N. Seale, MB BChir, MD, Steelhouse Lane, Birmingham B4 6NH, United Kingdom \\ (E-mail: anna.seale@bch.nhs.uk). \\ J Thorac Cardiovasc Surg 2016;151:618-20 \\ $0022-5223 / \$ 36.00$ \\ Copyright (c) 2016 by The American Association for Thoracic Surgery \\ http://dx.doi.org/10.1016/j.jtcvs.2015.11.040
}

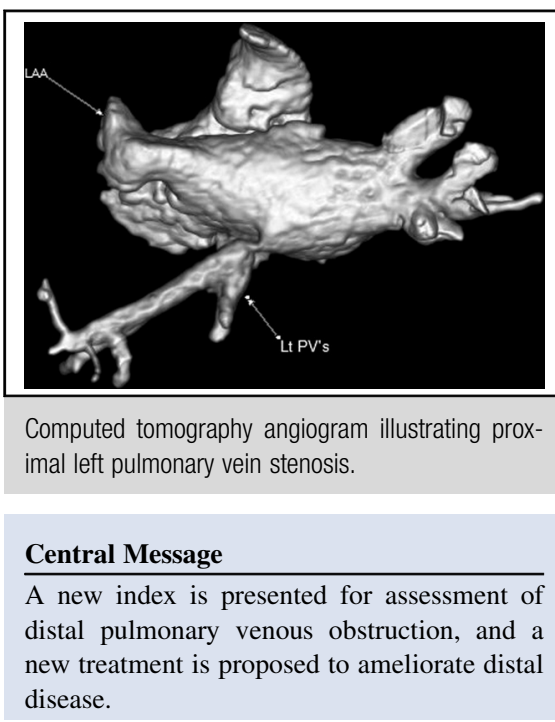

See Article page 657.

See Editorial Commentary page 667.
The fields of pediatric cardiology and cardiothoracic surgery have progressed substantially during the past 50 years, but some conditions are still extremely resistant to treatment; pulmonary vein stenosis is one such lesion. In the past 5 years, important advances have been made in our understanding of this disease, and the team from Hospital for Sick Children in Toronto should be commended for their dedication into leading research in this particular field.

Pulmonary vein stenosis is a life-threatening and challenging condition in which the pulmonary veins are narrowed, resulting in obstruction of blood flow back to the heart. The disease is often progressive, leading to generalized narrowing of the pulmonary veins upstream (distal) from the original site of obstruction; in some cases, atresia may develop. ${ }^{1}$ This results in raised pulmonary venous pressure and pulmonary edema, often leading to progressive pulmonary hypertension, right heart failure, and death. Development of a major venous collateral network can occur and may be associated with improved outcome. ${ }^{1}$ Neoproliferation of cells ${ }^{2}$ is responsible for the pulmonary venous narrowing, but the exact pathophysiology remains unknown.

Our lack of understanding of this condition likely accounts for the many types of surgical and catheter interventions; still, we have not managed to find the optimal treatment. Introduction of the "sutureless" surgical technique has helped in treating proximal disease,, 3 but results remain disappointing in cases of distal disease. An aggressive, early combination of both catheter and surgical interventional strategies may be the most effective, particularly in young and small patients, for whom the disease process can be particularly active. ${ }^{5}$ However, because of the progressive nature of pulmonary vein stenosis, the most important prerequisite for a successful outcome is to achieve complete abolition of the stenosis at an early stage, and before progression of the disease distally. The optimal initial strategy is likely to depend on local expertise, but repeated interventions, both surgical and with a catheter, should be contemplated. Mortality and morbidity are substantial, and even balloon angioplasty has been recently associated with significant risk of neurologic injury. ${ }^{6}$

An understanding of the limitations of imaging modalities is vital when diagnosing proximal pulmonary vein stenosis. Diagnosis can be particularly difficult with echocardiography alone. In $26 \%$ of cases of primary pulmonary vein stenosis, the stenosis was not diagnosed on echocardiogram but rather at cardiac catheterization or surgery. ${ }^{1}$ Close observation, and a high index of suspicion is required, with further imaging recommended, using computed tomography, cardiac magnetic resonance imaging, or angiography if obstruction is of concern. Cardiac magnetic resonance imaging is particularly helpful, as it not only delineates pulmonary venous anatomy, but also blood flow redistribution in the pulmonary veins and arteries.

But how do we know when distal disease is present? Determining whether the upstream vessels are involved in the disease process can be very difficult; decisions are often 
made after subjective interpretation of angiography performed in the cardiac catheterization laboratory. Diagnosis of distal disease is vital, as this will influence whether surgical interventions, which really treat only proximal disease, are likely to be beneficial. In addition, diagnosis can help predict long-term outcome.

Lo Rito and colleagues ${ }^{8}$ have suggested a novel technique to make objective measurements of the distal pulmonary venous vasculature using cardiac magnetic resonance imaging and computed tomography, thereby providing potential to diagnose patients with diffuse distal disease. This method is crucial for identifying patients more likely to respond to current surgical treatments and those that may be candidates for more novel medical therapies for distal disease. This novel and quite complex approach may be used additionally to quantify response to therapies over time. A comparison of computed tomography and cardiac magnetic resonance imaging, in measuring this new index, would have been interesting to see. Added utility would come from developing a "cut-off" value of the upstream, total, cross-sectional area index, below which surgical intervention can be considered futile.

Treatment of distal stenosis is not amenable to surgical or catheter intervention, so attention has turned to novel medical therapies to treat distal disease. Previous studies have investigated the mechanisms responsible for progression of pulmonary vein stenosis. Histologic studies have shown a variable manifestation of intimal and medial interstitial fibromuscular proliferation, together with fibrotic displacement of the muscle bundles in the venous wall. This process results in occlusion of the lumen of one or more of the pulmonary veins connecting the lungs to the left atrium. Most commonly, the thickening of intimal tissue occurs at the junction where the left atrium meets the pulmonary vein; the narrowing extends along the pulmonary vein toward the hilum of the lung.

Various cell types have been proposed as the source of neoproliferation. In 2000, Sadr and colleagues ${ }^{9}$ studied pulmonary venous tissue from 10 children who had congenital pulmonary vein stenosis in a normally connected heart. No evidence was found for thrombosis, inflammation, or fibrosis; however, evidence of myofibroblastic proliferation was present. Myofibroblasts are a progenitor cell for myocytes and fibroblasts, and they retain the ability to differentiate into either cell type depending on environmental factors. The authors proposed that congenital pulmonary vein stenosis could be treated with agents that arrest or eradicate the neoproliferative process, such as radiation, chemotherapy, or gamma interferon.

A study in 2006 by Riedlinger and colleagues ${ }^{10}$ showed that expression of various receptor tyrosine kinases and some ligands raised the possibility of an autocrine or paracrine role for these proteins in the pathogenesis of the intimal occlusive lesion seen in pulmonary vein stenosis.
Clearly, an understanding of these processes would help in development of treatments for pulmonary vein stenosis. Myofibroblastic proliferation occurs in desmoid tumors of infancy as well, and this led Rehman and colleagues ${ }^{11}$ to undertake a chemotherapeutic trial using vincristine and methotrexate in infants and children who had progressive multivessel intraluminal pulmonary vein stenosis. Success was limited.

Animal models have been used to investigate the pathologic changes in pulmonary vasculature that occur with pulmonary venous obstruction. LaBourene and colleagues, ${ }^{12}$ in 1990 , banded the pulmonary veins in piglets and studied hemodynamic, histologic, and biochemical changes in the pulmonary vasculature over time. From the Toronto group, Kato and colleagues ${ }^{13}$ used a similar animal model in 6 piglets that underwent bilateral pulmonary venous banding and showed endothelialmesenchymal transition. Tissues from vessels upstream of the banded pulmonary veins were associated with robust expression of transforming growth factor (TGF- $\beta$ ).

Zhu and colleagues ${ }^{14}$ again used the piglet model to investigate the effect of losartan on the progression of the stenotic process. They hypothesized that losartan has an inhibitory effect on TGF- $\beta$ and hence may modify the progressive stenosis seen in distal veins. They found that losartan significantly lowered the ratio of pulmonary artery to systemic blood pressure, and diminished intimal hyperplasia. The mechanism remains unclear. No difference was found in TGF- $\beta$ levels between the groups with, versus without, losartan; however, a difference was found in vascular endothelial cadherin levels, which they thought was indicative of diminished endothelial integrity.

Clearly, much work remains to be done in establishing the pathologic pathways that lead to progressive distal venous obstruction, and in translating this knowledge to humans. However, this work is extremely exciting and innovative, and explores the potential for postinterventional therapies to reduce the effect of distal disease. Such a reduction would be particularly helpful for patients considered to be at high risk of developing postoperative stenosis.

The imaging techniques of Lo Rito and colleagues ${ }^{8}$ may help in identifying such high-risk groups, and monitoring the effect of novel therapies. Determining whether losartan has a role in reversing established disease would be extremely interesting; hopefully, the research team will investigate this possibility. Future work is likely to involve clinical trials in humans, and due to the rarity of this disease, such investigation is likely to be multi-institutional and multinational. We sincerely hope that the pediatric cardiac community can come together to make such trials a reality.

Pulmonary vein stenosis is frequently a progressive disease leading to generalized narrowing of the pulmonary veins, and in some cases, atresia. The best way to prevent progression is to identify and treat the stenosis in the first 
place, so distal disease does not have the chance to occur. The team from Toronto $^{8}$ proposes a new index of pulmonary vein cross-sectional area, measured using cardiac magnetic resonance and computed tomography, as a tool to detect patients who are likely to have distal disease and hence a worse prognosis. They have previously proposed losartan as a medical treatment that may have a role in preventing distal disease. This development is exciting, and if confirmed, would represent a real advance in therapeutic options.

So, are we at a stage where we can prevent progression of pulmonary vein stenosis? No doubt we are closer, but much more work is needed, and clearly, collaborative medical trials are the optimal way to progress. For the present, established distal pulmonary venous disease remains an extremely challenging and resistant condition to treat.

\section{References}

1. Seale AN, Webber SA, Uemura H, Partridge J, Roughton M, Ho SY, et al. Pulmonary vein stenosis: the UK, Ireland and Sweden collaborative study. Heart. 2009; $95: 1944-9$.

2. Edwards JE. Congenital stenosis of pulmonary veins. Pathologic and developmental considerations. Lab Invest. 1960;9:46-66.

3. Lacour-Gayet F, Rey C, Planche C. Pulmonary vein stenosis. Description of a sutureless surgical procedure using the pericardium in situ. Arch Mal Coeur Vaiss. 1996;89:633-6 [In French].

4. Najm HK, Caldarone CA, Smallhorn J, Coles JG. A sutureless technique for the relief of pulmonary vein stenosis with the use of in situ pericardium. $J$ Thorac Cardiovasc Surg. 1998;115:468-70.
5. Quinonez LG, Gauvreau K, Borisuk M, Ireland C, Marshall AM, Mayer JE, et al. Outcomes of surgery for young children with multivessel pulmonary vein stenosis. J Thorac Cardiovasc Surg. 2015;150:911-7.

6. Esch JJ, Porras D, Bergersen L, Jenkins KJ, Marshall AC. Systemic embolic complications of pulmonary vein angioplasty in children. Pediatr Cardiol. 2015;36:1357-62.

7. Roman KS, Kellenberger CJ, Macgowan CK, Coles J, Redington AN, Benson LN, et al. How is pulmonary arterial blood flow affected by pulmonary venous obstruction in children? A phase-contrast magnetic resonance study. Pediatr Radiol. 2005;35:580-6.

8. Lo Rito M, Gazzaz T, Wilder TJ, Vanderlaan RD, Van Arsdell GS, Honjo O, et al. Pulmonary vein stenosis: Severity and location predict survival after surgical repair. J Thorac Cardiovasc Surg. 2016;151: 657-66.

9. Sadr IM, Tan PE, Kieran MW, Jenkins KJ. Mechanism of pulmonary vein stenosis in infants with normally connected veins. Am J Cardiol. 2000;86: 577-9. A10.

10. Riedlinger WF, Juraszek AL, Jenkins KJ, Nugent AW, Balasubramanian S, Calicchio ML, et al. Pulmonary vein stenosis: expression of receptor tyrosine kinases by lesional cells. Cardiovasc Pathol. 2006;15:91-9.

11. Rehman M, Jenkins KJ, Juraszek AL, Connor JA, Gauvreau K, Muneeb M, et al. A prospective phase II trial of vinblastine and methotrexate in multivessel intraluminal pulmonary vein stenosis in infants and children. Congenit Heart Dis. 2011;6:608-23.

12. LaBourene JI, Coles JG, Johnson DJ, Mehra A, Keeley FW, Rabinovitch M. Alterations in elastin and collagen related to the mechanism of progressive pulmonary venous obstruction in a piglet model. A hemodynamic, ultrastructural, and biochemical study. Circ Res. 1990;66:438-56.

13. Kato H, Fu YY, Zhu J, Wang L, Aafaqi S, Rahkonen O, et al. Pulmonary vein stenosis and the pathophysiology of "upstream" pulmonary veins. J Thorac Cardiovasc Surg. 2014;148:245-53.

14. Zhu J, Ide H, Fu YY, Teichert AM, Kato $H$, Weisel RD, et al. Losartan ameliorates "upstream" pulmonary vein vasculopathy in a piglet model of pulmonary vein stenosis. J Thorac Cardiovasc Surg. 2014;148: 2550-7. 